\title{
RESULTADOS DA APLICAÇÃO DA INOVAÇÃO NA INTERNACIONALIZAÇÃO DE EMPRESAS EXPORTADORAS
}

\author{
Júlio César Zilli ${ }^{1}$ \\ Janini Cunha de Borba ${ }^{2}$ \\ Fernando Locks Machado ${ }^{3}$
}

\begin{abstract}
This article aims to identify the effects of applying innovation and the participation and generation of innovation in exporting companies in the south of Santa Catarina. It was characterized as a descriptive, bibliographic and field research with a quantitative approach. The population was composed of 108 exporting companies belonging to AMREC, with the participation of 47 companies, composing a non-probabilistic sample. The data were collected from a questionnaire applied via Google Forms. The results of the application of innovation were an increase in revenue in terms of the financial area, brand value in the domestic market and an increase in the final quality of the product. In the participation and generation of innovative practices, the highlight was the development of new products and processes and the improvement of support for systems that compete in the areas of maintenance, accounting or information technology.
\end{abstract}

Keywords: innovation; internationalization; export; international market.

Resumo: Este artigo tem por objetivo identificar os efeitos da aplicação de inovação e a participação e geração da inovação nas empresas exportadoras do Sul de Santa Catarina. Caracterizou-se como uma pesquisa descritiva, bibliográfica e de campo com abordagem

\footnotetext{
${ }^{1}$ Programa de Pós Graduação em Engenharia e Gestão do Conhecimento - EGC/UFSC. Grupo de Pesquisa Gestão e Estratégia em Negócios Internacionais - GENINT/UNESC.E-mail: zilli42@ hotmail.com

${ }^{2}$ Grupo de Pesquisa Gestão e Estratégia em Negócios Internacionais - GENINT/UNESC. E-mail: janiniborba@outlook.com

${ }^{3}$ Grupo de Pesquisa Gestão e Estratégia em Negócios Internacionais - GENINT/UNESC. E-mail: locksmahado.fernando@gmail.com
} 
quantitativa. A população foi composta por 108 empresas exportadoras pertencentes a AMREC, com a participação de 47 empresas, compondo uma amostra não probabilística. Os dados foram coletados a partir de um questionário aplicado via Google Forms. Os resultados da aplicação de inovação foram o aumento de faturamento no que tange a área financeira, valor da marca no mercado interno e aumento da qualidade final do produto. Na participação e geração de práticas inovadoras destacaram-se o desenvolvimento de novos produtos e processos e a melhoria do suporte para os sistemas que competem as áreas da manutenção, contabilidade ou informática. Palavras-chave: inovação; internacionalização; exportação; mercado internacional.

\section{INTRODUÇÃO}

As últimas seis décadas foram marcadas por uma diminuição das barreiras geográficas nas relações entre diferentes países do mundo, fenômeno ao qual, de maneira simplista, costuma-se designar como globalização. Incentivado pelo aprimoramento tecnológico - e, mais precisamente, pelo advento da internet - esse fenômeno tem estreitado cada vez mais as parcerias comerciais firmadas entre empresas para além de suas fronteiras nacionais. Evidenciase como uma expansão global dos mercados e estabelece novas formas de organização da produção. Tal configuração não afeta apenas empresas, mas a sociedade de modo geral, causando impactos na política e na economia, exigindo de indivíduos e organizações mudanças significativas na forma de gestão e operação, em todos os setores (Loureiro; Santos, 1991).

Essas transformações têm mostrado certa correlação com a importância da inovação para a internacionalização, dentro do contexto empresarial. Estudos apresentam a relação desse fenômeno com teorias macroeconômicas bem estabelecidas, as quais mostram uma associação entre inovação e desempenho de exportação. A ideia é que a inovação de produtos e processos é um fator essencial para uma inserção exitosa de empresas em mercados estrangeiros. Isso porque a adoção da inovação estabelece uma vantagem competitiva para essas empresas, baseada em produtos e processos diferenciados (Bustos, 2011; Caldera, 2010; Melitz, 2003). Da mesma forma, estudos empíricos em nível microeconômico fornecem evidências da interação entre práticas inovadoras e exportação. No entanto, a maioria desses estudos considera 
pesquisa e desenvolvimento (P\&D), e inovação como práticas equivalentes, o que dificulta uma análise mais precisa do fenômeno (Cassiman; Golovko, 2011).

A causalidade entre exportação e inovação ainda é, portanto, uma questão em debate. Alguns modelos estabelecem, inclusive, que a própria internacionalização pode configurar-se como um processo inovador dentro das organizações. De maneira semelhante, as exportações podem gerar inovação, de acordo com teorias endógenas de crescimento (Grossman; Helpman, 1991). Logo, depreende-se que a internacionalização das empresas e a aplicação de práticas inovadoras possuem uma relação recíproca, sendo que uma pode ser causa da outra. Esses pressupostos motivaram a reflexão acerca do tema, sendo responsáveis por nortear os autores deste estudo na definição do problema de pesquisa: quais os efeitos da aplicação de inovação e a participação e geração da inovação nas empresas exportadoras do Sul de Santa Catarina?

Haja vista o interesse dos pesquisadores, bem como a viabilidade do estudo, o presente estudo limitou-se à região Sul de Santa Catarina, tendo como foco a Associação dos Municípios da Região Carbonífera (AMREC) ${ }^{4}$. Assim, além da questão norteadora, o locus da pesquisa também foi determinante para a definição do objetivo geral do estudo: identificar os efeitos da aplicação de inovação e a participação e geração da inovação nas empresas exportadoras do Sul de Santa Catarina.

A apresentação do estudo, seus procedimentos e resultados foi estruturada neste artigo da seguinte maneira: primeiro, são apresentados os principais conceitos acerca da internacionalização e da inovação; segue-se à apresentação dos procedimentos metodológicos e à coleta dos dados; os objetos de estudo são caracterizados; passa-se aos resultados da pesquisa e suas análises; e, por fim, são feitas as considerações finais, agradecimentos e referências.

\footnotetext{
${ }^{4}$ Associação de municípios localizada no Sul de Santa Catarina, a qual tem como objetivos e finalidades ampliar e fortalecer a capacidade administrativa, econômica e social dos municípios que dela fazem parte e promover a cooperação intermunicipal e intergovernamental dos mesmos (AMREC, 2020).
} 


\section{FUNDAMENTAÇÃO TEÓRICA}

A globalização, que corresponde a uma expansão dos mercados por todo o mundo e à estruturação de novas formas de organização da produção, tem se configurado como um fenômeno emergente entre meados do século XX e que está se consolidando agora, no século XXI. No entanto, o processo de globalização esboçou seus primeiros sinais já entre os séculos XV e XVI, com a difusão do capitalismo, fortemente impulsionada pelas grandes navegações. A diferença entre a expansão marítima e o momento presente é que, hoje, os principais atores não são mais nações e seus impérios, mas sim empresas de diferentes países (Goulart; Arruda; Brasil, 1994).

Portanto, para que se possa compreender melhor essa dinâmica entre internacionalização e sua relação com a inovação, tal conteúdo é abordado a seguir. Apresentase a progressão dos efeitos desse fenômeno, seu contexto e a sua relação com as práticas inovadoras adotadas pelas organizações, como forma de constituir o embasamento teórico aplicado a este estudo.

\subsection{INTERNACIONALIZAÇÃO DE EMPRESAS E INOVAÇÃO}

No final da década de 1940, o comércio entre países começou a dar os seus primeiros passos rumo à internacionalização das negociações. Essa nova conformação, ocorrida após o término da Segunda Guerra Mundial, se deu pelas ações coordenadas entre países, que, devastadas pela guerra, buscavam reestrutura a economia em uma escala global. Não apenas essa integração entre nações foi importante para essa nova dinâmica, mas também o acirramento da competição entre empresas, em mercados cuja escassez de produtos não era mais o fator preponderante para o consumo. Isso tudo fez com que empresas de todos os continentes começassem a considerar o cenário internacional como alternativa para seu desempenho (Goulart; Arruda; Brasil, 1994).

A internacionalização dos negócios teve como reflexo a propagação de organizações empresariais multinacionais, distribuídas por todo o globo. A consequência disso foi uma homogeneização geral de produtos, ou seja, produtos padronizados, vendidos em praticamente 
todos os países e regiões do mundo, na mesma forma e composição. Essa seria a primeira e mais evidente característica que marcaria a chegada do fenômeno chamado de globalização dos mercados (Levitt, 1983).

Entretanto, é importante salientar a divergência existente entre a ideia de padronização de produtos e processos, e a demanda pela customização/adaptação de produtos. Autores como Melin (1992) ressaltam que o comportamento dos consumidores é equivalente apenas para produto, serviços e segmentos específicos. A maioria dos bens e serviços comercializados ainda sofre influência das diferenças socioeconômicas, geopolíticas, culturais e tecnológicas entre os diferentes mercados-alvo. Há produtos e serviços no comércio internacional que, apesar de possuírem similaridades entre si, precisam ser adaptados aos anseios e necessidades do mercado ao qual se destinam. Dito de outra forma, a globalização pode levar a uma tendência da padronização de produtos e processos, mas não padroniza preferências de consumidores. Assim, se pode caracterizar a internacionalização como a atuação em diferentes nações, por meio da movimentação de fatores de produção, transferência de capital, desenvolvimento de projetos em parceria com estrangeiros, ou, de forma mais simplista, a comercialização de produtos entre empresas de dois países distintos. Sob uma visão mais ampla e voltada aos aspectos econômicos das nações, represente o fluxo das negociações de matéria-prima, produtos e serviços, dinheiro e pessoas entre países (Meloan; Graham, 1998).

Ainda acerca da internacionalização, é possível destacar caráter essencial que esse assunto passou a ter na estratégia organizacional das empresas. Ele não é mais visto como fator secundário ou consequente em uma estratégia de longo prazo da empresa, mas sim como um pressuposto inserido no planejamento estratégico das organizações em atuação nacional ou internacional. Diante disso, se destaca a expansão de mercados como estratégia empresarial, desencadeada por perspectivas de esgotamento no mercado interno e as quais influenciam diretamente na tomada de decisão das empresas. Há também a possibilidade de novos negócios no mercado externo como oportunidade para a organização, influenciando, do mesmo modo, na composição do planejamento estratégico empresarial (Costa; Añes; Mol; Damasceno, 2017).

Nesse contexto, autores como Almeida (2007) afirma que, para as empresas que passam a enfrentar limitações no mercado doméstico, uma das principais saídas à continuidade de seu crescimento é a expansão das operações para novos mercados. Esse processo se inicia, quase 
sempre, com operações de exportação, chegando a outros estágios, como a internacionalização de escritórios e parques fabris. Ainda assim, a saturação de mercados tem se caracterizado como um elemento marcante no comércio global do século XXI. Essa alta competitividade entre empresas pressiona cada vez mais as organizações no sentido de adotarem estratégias e práticas inovadoras, ou seja, incutindo a inovação como princípio fundamental em seus planejamentos, mesmo quando a busca pela internacionalização seja encarada como uma oportunidade.

Os estudos sobre a inovação são segmentados e duas abordagens principais: a econômica neoclássica e a teoria evolucionista. A visão econômica neoclássica trata da racionalidade absoluta quanto ao comportamento humano e a expectativa do equilíbrio das relações econômicas. Disso decorreria a inovação enquanto consequência de um processo mecânico, linear e natural, por conta da atividade produtiva. Sob essa ótica, a inovação surge do ambiente interno do sistema produtivo. Já a evolucionista enxerga a expectativa de racionalidade de maneira mais flexível e desconsidera a objetividade capaz de maximizar resultados. É voltada ao caráter dinâmico, cumulativo e não linear do processo de mudança, em que há o reconhecimento de uma competição dinâmica entre os elementos que constituem a produção das organizações. Preocupa-se com a investigação da realidade das empresas e com a capacidade de aprendizado em relação à inovação, além de considerar estratégias e atividades de adaptação, integração e reconfiguração, tanto de habilidades, quanto de recursos. Essas concepções se relacionam diretamente com os processos de inovação, especificamente em relação ao modo como as empresas gerenciam esses processos. Isso leva a duas abordagens distintas do processo de inovação: a fechada a aberta (Engeroff; Balestrin, 2008; Tidd; Bessant; Pavit, 2003; Teece; Pisano, 1994; Vvan Der Meer, 2007).

A abordagem fechada baseia-se no controle sobre o processo de inovação, utilizando como ferramenta para a formalização das práticas inovadoras o Funil de Inovação. Esse modelo pode é composto por um funil de fases, as quais representam o processo de inovação. Entre cada fase há portões que visam "filtrar" potenciais projetos que não trarão bons resultados, ou seja, aqueles que não atendem aos critérios da inovação de sucesso para esse sistema, que são a novidade, a viabilidade e a efetividade (Cooper, 1992).

$\mathrm{Na}$ entrada do funil estão as ideias, convertidas posteriormente em projetos, seguindo para a transformação de projetos em produtos, processos e negócios. O resultado está ligado a 
novos produtos, tecnologia ou oportunidades de nichos não explorados ainda pela empresa. $\mathrm{Na}$ abordagem fechada da inovação, o foco está intimamente relacionado às capacidades internas da organização, sendo que apenas o P\&D da própria empresa é que perpassa pelas etapas do funil (Tidd; Bessant; Pavitt, 2003).

A abordagem da inovação aberta é fundamentada na utilização de caminhos internos ou externos que permitam avançar no desenvolvimento de novas tecnologias. Em outras palavras, fluxos de entrada e saída de conhecimento são utilizados de forma intencional, favorecendo a inovação interna e ampliando mercados e fontes de inovação externas. Tal abordagem demanda um diferente modo de pensar e seus meios de utilização podem variar, sendo eles colaborativos ou de simples troca, como relacionamento com outras empresas, com universidades e institutos de pesquisa, com clientes, fornecedores e também ao importar exportar ideias (Van Der Meer, 2007).

A delimitação da inovação aberta considera ainda que: (i) é necessário trabalhar com pessoas que estejam capacitadas, tanto dentro, quanto fora da empresa, ou ainda, P\&D externo pode criar valor e P\&D interno é necessário para captar e incorporar à empresa tal valor; (ii) não é imprescindível que haja o desenvolvimento de pesquisas internas para lucrar com a inovação; (iii) estabelecer modelo de negócio sólido pode ser melhor do que garantir que a empresa seja a primeira a colocar uma inovação no mercado; (iv) o ganho provém dos projetos de inovação e recomenda-se compartilhar e adquirir ideias que permitam alavancar o modelo de negócios (Engeroff; Balestrin, 2008).

É relevante destacar que as empresas terão que considerar, cada vez mais, a inserção da inovação aberta no âmbito empresarial, além de definirem cooperativamente as suas estratégias inovadoras, tanto as locais, quanto as globais. A utilização e o compartilhamento de ideias interna e externamente são essenciais para o estabelecimento de práticas inovadoras, especialmente aquelas voltadas aos mercados internacionais. Isso porque o atual paradigma da inovação converge não apenas para a criação de produtos e processos inovadores, mas também para o estabelecimento e renovação de soluções e modelos de negócios inovadores por todo o mundo. $\mathrm{O}$ desafio às empresas é, portanto, gerenciar a inovação aberta não apenas dentro de sua estrutura, mas também no contexto dos sistemas nacionais e internacionais de inovação nos quais se inserem (Chesbrough, 2003).

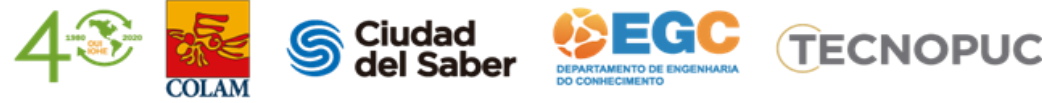




\section{PROCEDIMENTOS METODOLÓGICOS}

O método qualitativo tem por base princípios naturalistas e vem sendo vastamente utilizado no campo das ciências sociais, por sua vez, esse método objetiva explicar conceitos, comportamentos, percepções e avaliação das pessoas, em termos realistas. No método quantitativo tem-se maior ênfase nos dados numéricos, sua utilização está atrelada a medições e repetição das mesmas, e que por ventura necessitem ser generalizadas a fim de compará-las entre outras populações (Estrela, 2018).

Tendo em vista que a presente pesquisa tem como objetivo identificar o perfil, os resultados que a aplicação da inovação traz para as empresas exportadoras, bem como, a participação e geração da inovação, aderiu-se a abordagem quantitativa para a execução da mesma. Essa designação tem como base as premissas discutidas anteriormente, sendo que por averiguação tem maior consonância com o objetivo proposto para este estudo.

Com relação aos fins de investigação, caracteriza-se como uma pesquisa descritiva, visto que não há interferência do pesquisador, sendo que o mesmo, analisa, registra e interpreta os fatos dispostos. A pesquisa descritiva tem por finalidade observar os fenômenos ou sistemas técnicos, contudo, sem que haja a influência do investigador (Barros; Lehfeld, 2007). Tal característica pode ser observada neste estudo diante das informações coletadas que foram fornecidas pelas próprias empresas, sem que houvesse interferência dos pesquisadores.

Quanto aos fins de investigação, trata-se de uma pesquisa de campo que teve como auxílio a aplicação de um questionário online, além do apoio da pesquisa bibliográfica, utilizada para explicar e discutir informações de bases teóricas publicadas em artigos, revistas científicas e livros, possibilitando ao autor a consulta a diferentes opiniões de um mesmo assunto abordado (Nascimento, 2012).

A definição da população e amostra envolve muitos sujeitos na pesquisa, pois o objetivo é generalizar os resultados obtidos. Para tanto, deve-se delimitar a população, definir o método de seleção da amostra (probabilístico, não probabilístico ou por julgamento), precisar o tamanho exigido na amostra e aplicar o procedimento de seleção. A composição da amostra deve retratar casos em que o conjunto é estatisticamente representativo, em virtude da generalização dos 
resultados (Creswell, 2010; Diehl; Tatim, 2004; Malhotra, 2005; Sampieri, Collado; Lucio, 2013).

Com base nas orientações dos autores acima referenciados, vale ressaltar que o Sul do Estado de Santa Catarina é subdividido em três microrregiões, caracterizadas como a Associação dos Municípios da Região Carbonífera (AMREC), Associação de Municípios da Região de Laguna (AMUREL) e Associação de Municípios do Extremo Sul Catarinense (AMESC). A AMREC, foco do estudo, é composta por 12 municípios: Criciúma (sede), Içara, Lauro Muller, Morro da Fumaça, Nova Veneza, Siderópolis, Urussanga, Forquilhinha, Cocal do Sul, Treviso Orleans e Balneário Rincão (AMREC, 2020).

Para determinar as empresas da AMREC aptas a participar da pesquisa (população), utilizou-se a listagem de empresas exportadoras do ano de 2018, disponibilizada pelo Ministério da Economia, no módulo Estatísticas de Comércio Exterior (Brasil, 2020). Filtrando-se pelo estado de Santa Catarina e posteriormente as cidades que compõe a AMREC, obteve-se a população de 139 empresas entre produtoras, trading companies e assessorias de comércio exterior. Definiu-se que a pesquisa seria aplicada somente entre as empresas produtoras, das quais podem importar matéria-prima e exportar seus produtos. Desta forma, após retirar estas empresas que não se encaixaram na população-alvo e aquelas que possuem filiais, a população de 139 se reduziu a 108 empresas exportadoras. Ao encontro do que orienta Lakatos e Marconi (2001) colher as informações de um grande grupo no todo é praticamente impossível, por isso a necessidade de definir uma amostra que represente o conjunto.

A partir das 108 empresas exportadoras, a pesquisa foi aplicada durante os meses de setembro, outubro e novembro de 2019 , pelo critério de disponibilidade de participação e pela acessibilidade junto às mesmas. Inicialmente efetuou-se o contato telefônico junto ao departamento de exportação de todas as empresas, explicando o objetivo da pesquisa e solicitando que o gerente de exportação, gerente de área ou coordenador de exportação respondessem o questionário enviado via Google Forms. Em um primeiro momento, no mês de setembro de 2019, 20 empresas responderam o instrumento, e novamente nos meses de outubro e novembro foi feita uma nova rodada de ligações, obtendo-se o retorno de 27 empresas. Ao final de novembro de 2019, a pesquisa foi encerrada, totalizando a participação de 47 empresas 
exportadoras do Sul de Santa Catarina (AMREC), caracterizando-se como uma amostra não probabilística, por conveniência (Malhotra, 2006).

Os dados de origem primária (Vegara, 2010), foram coletados por meio de um questionário (GIL, 1999) elaborado e adaptado a partir de alguns estudos efetuados em 2015, 2018 e 2019 e publicados por Zilli, Heinzen e Vieira (2015), Pereira, Zilli, Vieira e Volpato (2018), Dondossola, Zilli, Volpato e Vieira (2019), Zilli, Locks, Freire e Engel (2019), bem como Zilli e Freire (2020). Foram feitos testes junto a três profissionais que possuem experiência acadêmica e também vivência perante o mercado internacional, para verificar a consistência do instrumento de coleta, bem como verificar se a organização dos módulos e perguntas estavam adequadas e de fácil entendimento. Após o retorno dos profissionais foram feitos ajustes que proporcionaram a finalização do questionário,

A aplicação do instrumento ocorreu via Google Forms e foi estruturado em quadro módulos: Módulo I - Contexto Empresarial e Modelo de Gestão; Módulo II - Ingresso e Participação no Mercado Internacional; Módulo III - Estratégias, Posicionamento no Mercado Internacional e Redes de Cooperação; e Módulo IV: Modelo de Gestão e o Desenvolvimento de Práticas Inovadoras (transformadoras) perante o Mercado Internacional. Importante ressaltar que os resultados analisados neste artigo referem-se aos Módulos I e IV (foco nos efeitos da aplicação de inovação e a participação e geração da inovação. Essa segmentação foi feita para que cada módulo pudesse ser explorado em um estudo específico, voltado às particularidades das seções que estruturam o referido questionário.

Com relação a análise dos dados, a mesma foi feita por meio de frequência simples, pois de acordo com Duarte e Furtado (2014, p. 142): "Mais importante do que apontar a representatividade dos resultados quantitativos é refletir e interpretar o que significam, extrapolando para outras fontes e informações constantes no trabalho e fazendo inferências".

Por fim, vale ressaltar que todo o processo de construção da pesquisa contou com o apoio da Fundação de Amparo à Pesquisa e Inovação do Estado de Santa Catarina (FAPESC) e da Associação Catarinense das Fundações Educacionais (ACAFE), por meio da chamada pública 06/2017, contrato 2018TR1542 e protocolo de entrada 1673/2018, contemplando uma pesquisa com amplitude maior, intitulada "Do Sul Catarinense (AMREC) para o mundo: exportação de práticas e soluções inovadoras".

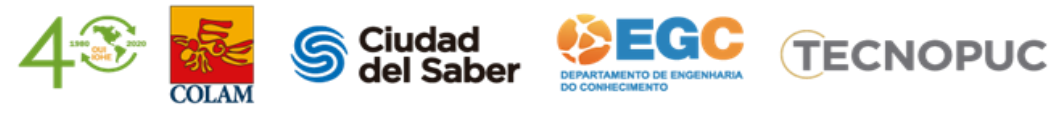




\section{APRESENTAÇÃO E DISCUSSÃO DOS RESULTADOS}

\subsection{CONTEXTO EMPRESARIAL E MODELO DE GESTÃO}

De acordo com o proposto, em identificar o perfil das empresas exportadoras da AMREC, o primeiro módulo aborda os setores de atuação, a cidade onde as empresas estão situadas, contrapondo com o porte e a composição do capital social das mesmas, além disso, faz menção ao ano de fundação, bem como acontece o direcionamento da produção e a forma de gestão dessas organizações.

Tabela 1 - Setor de atuação das empresas.

\begin{tabular}{|c|c|c|}
\hline SETOR DE ATUAÇÃO & QTDADE & $\%$ \\
\hline Agroalimentar & 1 & 2,13 \\
\hline Celulose e Papel & 1 & 2,13 \\
\hline Cerâmica & 12 & 25,53 \\
\hline Construção Civil & 2 & 4,26 \\
\hline Metal Mecânico e Metalurgia & 16 & 34,04 \\
\hline Móveis e Madeira & 2 & 4,26 \\
\hline Produtos Químicos e Plásticos & 13 & 27,66 \\
\hline TOTAL & 47 & 100,00 \\
\hline
\end{tabular}

Fonte: Elaborado pelos autores a partir dos dados coletados (2020).

Frente aos dados estabelecidos na Tabela 1, constata-se concentração de empresas nos setores cerâmico, metal mecânico e metalúrgico e o setor de produtos químicos e plásticos, que juntos compõem aproximadamente $88 \%$ da amostra deste estudo, condicionando um perfil industrial acentuado e de representatividade para a região e cidades onde as empresas estão situadas.

Dessa maneira, com a finalidade também de identificar a cidade sede das empresas, a Figura 1 ilustra a localidade das quais as respondentes deste estudo estão situadas. 
Figura 1 - Cidade sede das empresas.

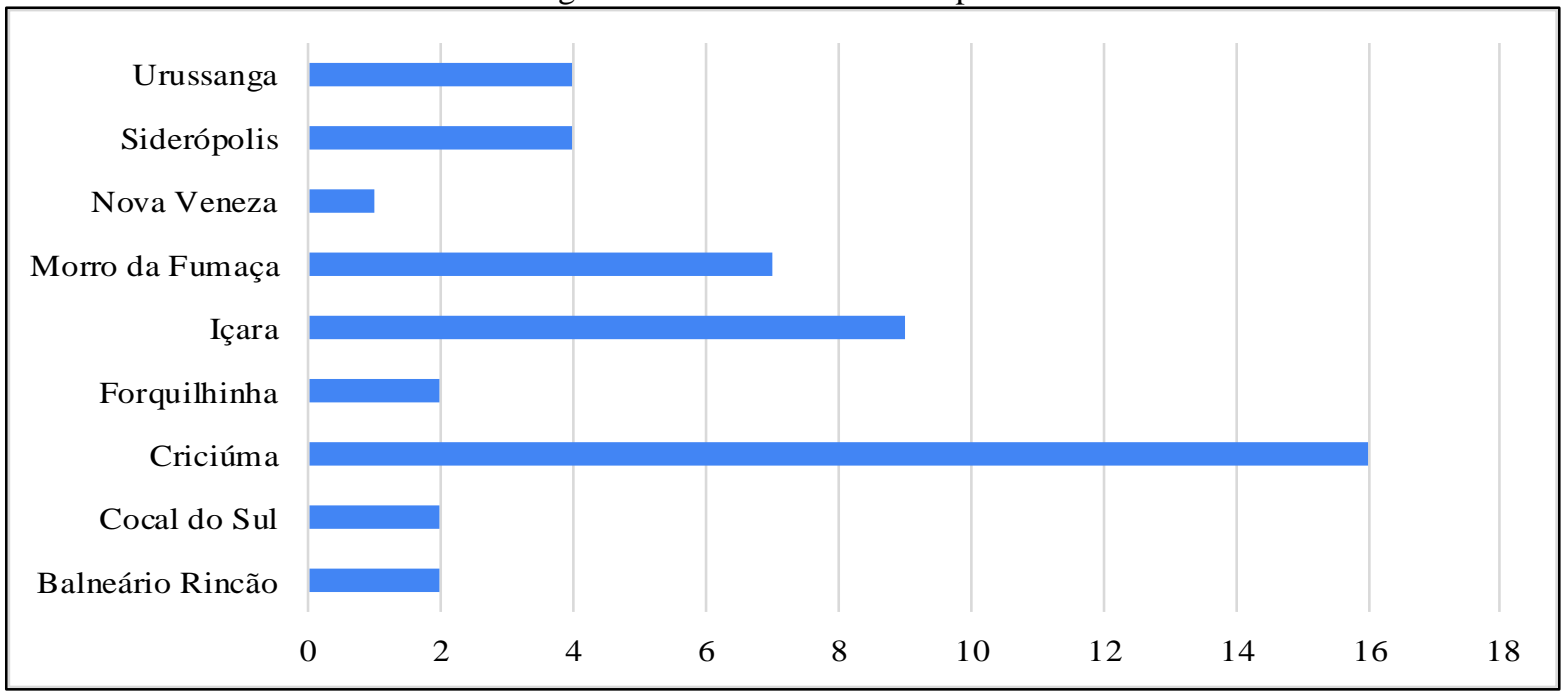

Fonte: Elaborado pelos autores a partir dos dados coletados (2020).

Fica evidente uma maior concentração de empresas, na cidade de Criciúma, onde estão alocadas 16 delas, Içara com 9 e Morro da Fumaça que possui 7 empresas neste estudo, estabelecendo uma parcela de 68\% das participantes dessa pesquisa. Diante do exposto, justifica-se a quantidade de firmas na cidade de Criciúma, pela mesma ser conhecida como polo industrial na região do Extremo Sul Catarinense.

De acordo com IBGE (2017), as três cidades citadas anteriormente, juntas possuem 12.146 empresas atuantes e uma média de PIB per capita de $\mathrm{R} \$ 36.125$, ademais, segundo Ministério da Economia (2019) são 100 empresas exportadoras pertencentes a estes três municípios, com destaque para Criciúma, que contempla 62 das organizações que operam com exportação. Outro dos questionamentos da pesquisa estava relacionado ao porte da empresa, a Figura 2 ilustra a distribuição por faixa de faturamento, delineando seu enquadramento. 
Figura 2 - Porte das empresas.

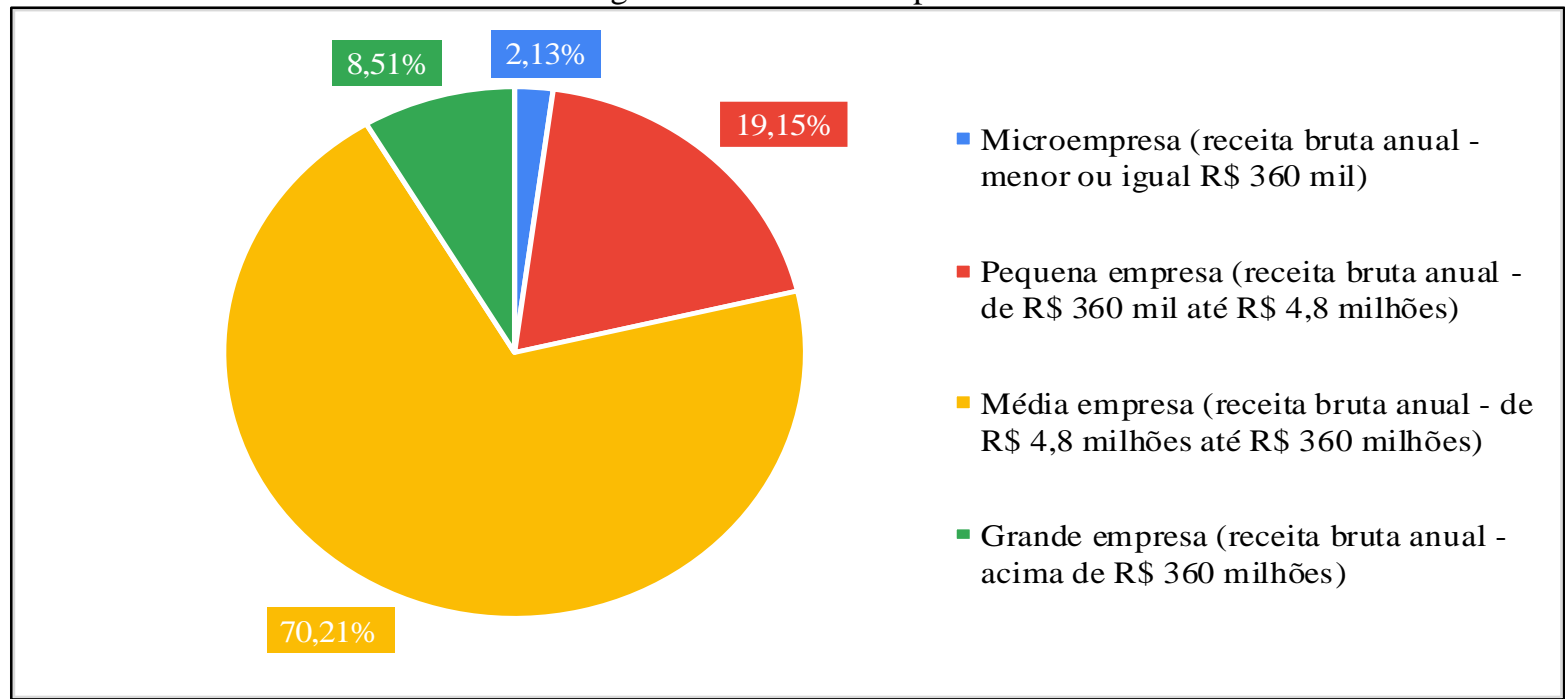

Fonte: Elaborado pelos autores a partir dos dados coletados (2020).

Em concordância com a Agência Nacional de Vigilância Sanitária - ANVISA (2019), o "Porte da empresa é a capacidade econômica da empresa, determinada de acordo com o seu faturamento anual bruto. Para o faturamento anual bruto, deve ser considerado o montante anual faturado pela matriz e suas filiais, se houver". Pelo fato do Brasil ter grande caracterização por pequenos empreendimentos, de acordo com o Data Sebrae (2020), a microrregião da AMREC contempla 42.796 empresas, das quais 45,27\% são classificadas como Microempresas e 41,03\% são Microempreendedores individuais, sendo que tais empresas estão divididas principalmente no setor de serviços e comércio.

Entretanto, os dados da pesquisa possibilitaram identificar a representatividade da média empresa, dentre as 47 respondentes, 70,21\% delas estão agrupadas nesse porte, seguida por uma parcela de 19,15\% de pequena empresa, constatando-se que a cultura exportadora na microrregião está alocada principalmente nas organizações de "maior" porte, além disso, relacionando com a composição do capital das empresas, como elenca a Tabela 2, em que $68 \%$ das firmas possuem seu capital $100 \%$ de origem nacional. 
Tabela 2 - Composição do capital das empresas.

\begin{tabular}{l|c|r}
\hline \multicolumn{1}{c|}{ \% DE COMPOSIÇÃO DO CAPITAL } & QTDADE & \multicolumn{1}{c}{$\%$} \\
\hline $100 \%$ nacional & 32 & 68,09 \\
\hline $75 \%$ nacional & 7 & 14,89 \\
\hline $25 \%$ nacional & 3 & 6,38 \\
\hline $100 \%$ internacional & 5 & 10,64 \\
\hline TOTAL & $\mathbf{4 7}$ & $\mathbf{1 0 0 , 0 0}$ \\
\hline
\end{tabular}

Fonte: Elaborado pelos autores a partir dos dados coletados (2020).

Diante da caracterização do ano de fundação das empresas, evidencia-se organizações que se inseriram no mercado a partir da década de 50, porém com predominância de ingresso entre os anos de 1981 e 2000, denotando empresas consolidadas e de longa atuação, com experiência de até 70 anos, conforme ilustra a Figura 3.

Figura 3 - Ano de fundação das empresas.

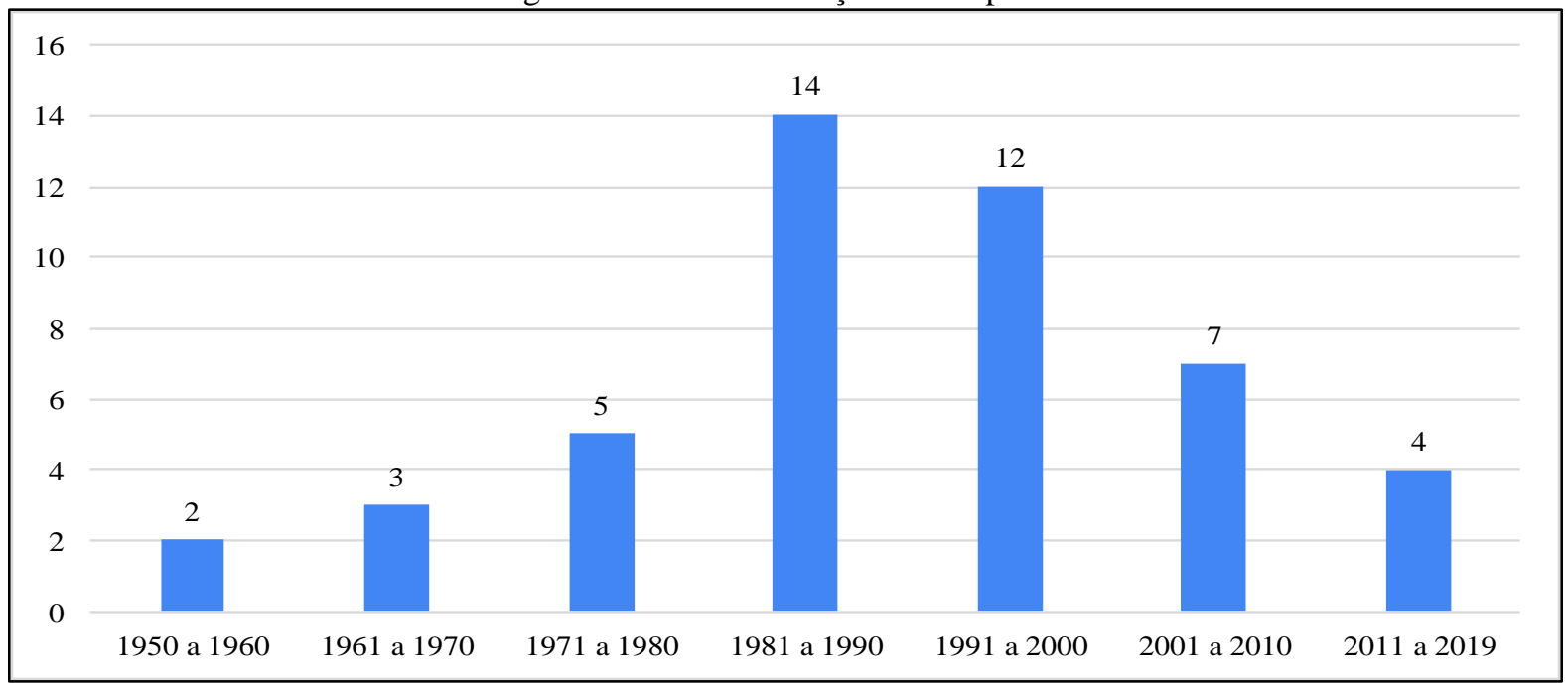

Fonte: Elaborado pelos autores a partir dos dados coletados (2020).

No que se refere ao questionamento em relação ao direcionamento da produção, a Tabela 3 retrata que os negócios com o mercado externo se dão primordialmente para a escoação dos excedentes. 
Tabela 3 - Direcionamento da produção das empresas.

\begin{tabular}{|c|c|c|}
\hline DIRECIONAMENTO & QTDADE & $\%$ \\
\hline Negócios somente com o mercado interno (Brasil) & 1 & 2,13 \\
\hline Negócios somente para o mercado externo (Exterior) & 1 & 2,13 \\
\hline $\begin{array}{l}\text { Negócios com o mercado interno (Brasil), porém com excedente para } \\
\text { o mercado externo (Exterior) }\end{array}$ & 43 & 91,49 \\
\hline $70-75 \% \mathrm{ME}-25-30 \% \mathrm{MI}$ & 1 & 2,13 \\
\hline Mercado Interno e externo, sem diferenciação de excedente. & 1 & 2,13 \\
\hline TOTAL & 47 & $\mathbf{1 0 0 , 0 0}$ \\
\hline
\end{tabular}

Fonte: Elaborado pelos autores a partir dos dados coletados (2020).

Aproximadamente $92 \%$ das empresas sinalizaram seus negócios com o mercado nacional, porém direcionando seus excedentes para a exportação. Essa situação pode ser atribuída pelo "comodismo" encontrado nas negociações nacionais, mantendo como prioridade as vendas internas, sem uma estratégia específica em relação as vendas para o mercado estrangeiro. Esta condição, é tratada na literatura como um dos principais motivadores no processo de internacionalização das empresas, visto que as mesmas encontram uma oportunidade de escoar àquela produção excedente e sem saída no âmbito nacional.

Com isso, a fim de revelar a forma de gestão das empresas, a Figura 4 elenca as respostas das participantes desse estudo.

Figura 4 - Forma de gestão das empresas.

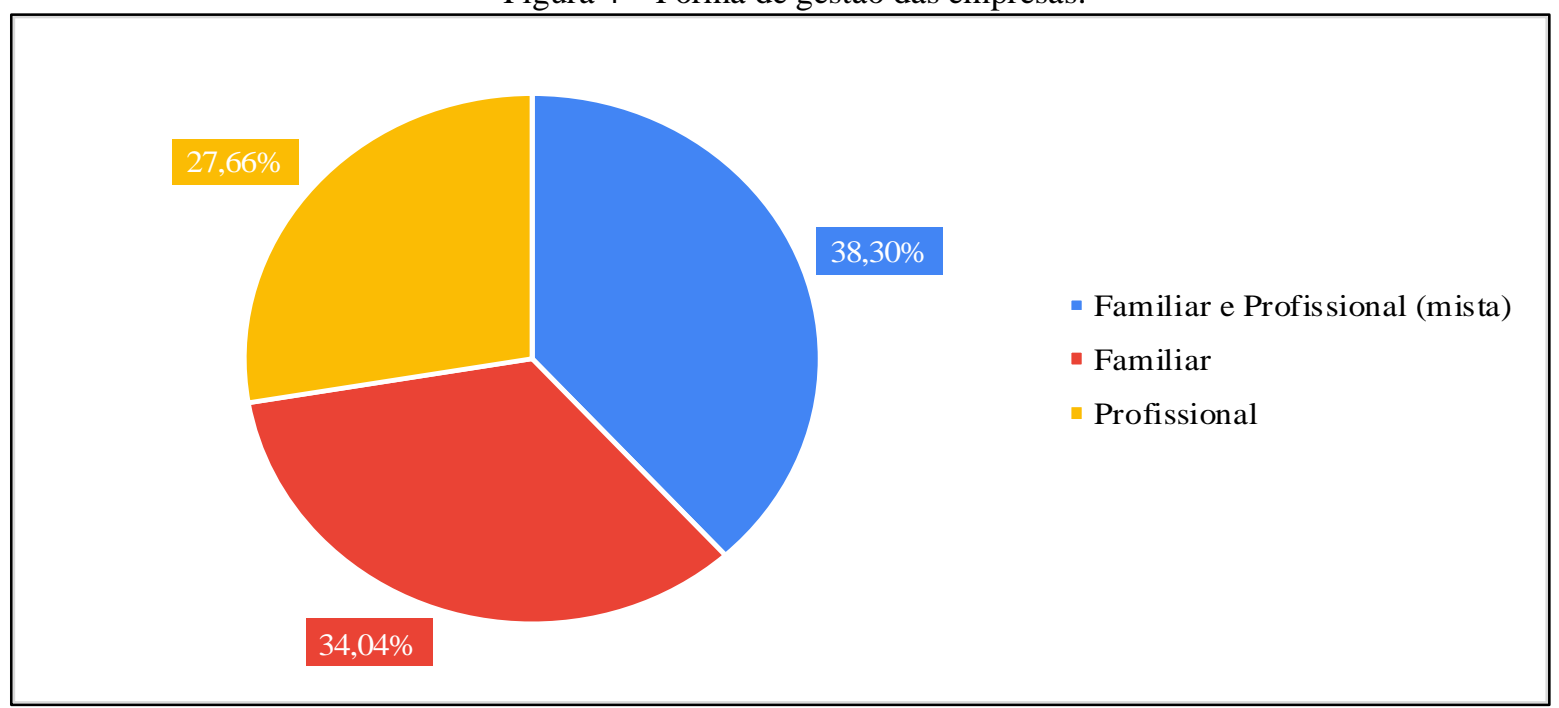

Fonte: Elaborado pelos autores a partir dos dados coletados (2020). 
A análise da Figura 4, permite averiguar uma distribuição equivalente entre as formas de gestão, demonstrando que não há concentração em uma que tenha maior destaque e que acentue um perfil entre as empresas, no entanto cabe destacar que a presença familiar é recorrente em quase $73 \%$ das organizações respondentes deste estudo.

\subsection{RESULTADOS DA APLICAÇÃO DA INOVAÇÃO NAS EMPRESAS}

$\mathrm{Na}$ intenção de dar continuidade à apresentação dos resultados deste estudo, esta seção objetivou elencar a discussão referente a questões do módulo IV, das quais tratam sobre os efeitos trazidos para a empresa a partir da aplicação da inovação. Para tanto, os questionamentos englobaram aspectos financeiros, mercado interno, clientes, produto, e por fim em relação a estratégia. A Tabela 4 apresenta os efeitos da aplicação de inovação em relação aos resultados financeiros.

Tabela 4 - Resultados financeiros obtidos com a aplicação da inovação.

\begin{tabular}{l|r|r}
\hline \multicolumn{1}{c|}{ RESULTADO } & QTDADE & \% \\
\hline Aumento da lucratividade & 6 & 12,77 \\
\hline Aumento do capital de giro & 5 & 10,64 \\
\hline Aumento do valor agregado do produto & 2 & 4,26 \\
\hline Aumento no faturamento & 18 & 38,30 \\
\hline Redução de custos & 4 & 8,51 \\
\hline Não sabe & 9 & 19,15 \\
\hline Nenhum & 3 & 6,38 \\
\hline TOTAL & $\mathbf{4 7}$ & $\mathbf{1 0 0 , 0 0}$ \\
\hline
\end{tabular}

Fonte: Elaborado pelos autores a partir dos dados coletados (2020).

A partir da leitura da Tabela 4 ficou evidente a representatividade do aumento no faturamento, apontado por 38,3\% das empresas respondentes, no entanto, também cabe destacar que cerca de $26 \%$ das empresas não sabem do impacto e não identificam nenhum resultado obtido, o que denota uma falta de controle e até mesmo uma certa indiferença em relação as práticas inovativas aplicadas pela organização.

Para tanto, além dos aspectos financeiros, a Tabela 5 também trata da relação da inovação com o mercado nacional, a partir da sua aplicação. 
Tabela 5 - Resultados no mercado interno obtidos com a aplicação da inovação.

\begin{tabular}{l|r|r}
\hline \multicolumn{1}{c|}{ RESULTADO } & QTDADE & \multicolumn{1}{c}{ \% } \\
\hline Aumento da competitividade & 3 & 6,38 \\
\hline Aumento do valor agregado & 12 & 25,53 \\
\hline Crescimento da marca & 6 & 12,77 \\
\hline Ganho de mercado & 15 & 31,91 \\
\hline Não sabe & 5 & 10,64 \\
\hline Nenhum & 6 & 12,77 \\
\hline TOTAL & $\mathbf{4 7}$ & $\mathbf{1 0 0 , 0 0}$ \\
\hline
\end{tabular}

Fonte: Elaborado pelos autores a partir dos dados coletados (2020).

De acordo com Miranda, Vasconcelos, Luca e Cabral (2015), a continuidade da empresa no mercado, diante do contexto empresarial competitivo e "agravado" pela internacionalização dos mercados demanda da necessidade permanente da inovação. Ou seja, os reflexos da inovação são de grande valia tanto no âmbito internacional, como na percepção dos clientes no mercado doméstico.

Diante do exposto, aos aspectos relacionados ao mercado interno, perante a inovação, a maior concentração de respostas esteve atrelada ao ganho de mercado e aumento do valor agregado, que juntas contemplaram 27 empresas que sinalizaram tais resultados. Entretanto 11 empresas não sabem identificar e não encontraram nenhum resultado em relação ao mercado interno por meio da aplicação de inovação.

No que tange os resultados obtidos com clientes a partir das práticas de inovação, a Tabela 6 evidencia tais respostas quanto a esse questionamento.

Tabela 6 - Resultados com clientes obtidos com a aplicação da inovação.

\begin{tabular}{l|r|r}
\hline \multicolumn{1}{c|}{ RESULTADO } & QTDADE & \% \\
\hline Aumento na atração de novos clientes & 7 & 14,89 \\
\hline Aumento na percepção de valor da marca & 17 & 36,17 \\
\hline Melhora no relacionamento com clientes & 10 & 21,28 \\
\hline Redução de custos com atração de clientes & 3 & 6,38 \\
\hline Não sabe & 5 & 10,64 \\
\hline Nenhum & 5 & 10,64 \\
\hline TOTAL & $\mathbf{4 7}$ & $\mathbf{1 0 0 , 0 0}$ \\
\hline
\end{tabular}

Fonte: Elaborado pelos autores a partir dos dados coletados (2020).

Perante os reflexos apontados pelas empresas com relação aos clientes impactados com a aplicação da inovação, concentrou-se um número de respostas no quesito aumento na 
percepção de valor da marca e melhora no relacionamento com clientes, totalizando 27 empresas, o que representa aproximadamente $58 \%$ da amostra deste estudo.

Seguindo ao próximo questionamento, a Tabela 7 elenca os resultados alcançados com a inovação em relação ao produto.

Tabela 7 - Resultados em relação ao produto obtidos com a aplicação da inovação.

\begin{tabular}{l|r|r}
\hline \multicolumn{1}{c|}{ RESULTADO } & QTDADE & \% \\
\hline Aumento da qualidade final & 17 & 36,17 \\
\hline Diferenciação do produto perante a concorrência & 6 & 12,77 \\
\hline Novos processos produtivos & 9 & 19,15 \\
\hline Redução dos custos de produção & 4 & 8,51 \\
\hline Não sabe & 7 & 14,89 \\
\hline Nenhum & 4 & 8,51 \\
\hline TOTAL & $\mathbf{4 7}$ & $\mathbf{1 0 0 , 0 0}$ \\
\hline
\end{tabular}

Fonte: Elaborado pelos autores a partir dos dados coletados (2020).

Perante a abordagem da inovação no contexto produtivo, Reichert, Camboim e Zawislak (2015) ressaltam que tal tema é definido como uma novidade, do qual sua aplicação proporciona retornos financeiros positivos às diversas áreas da empresa, e ainda contempla esforços de mudança, no escopo de adaptações em produtos, novos arranjos operacionais, dentre outras práticas que se estendem aos demais setores de uma organização.

Dessa forma, em relação aos impactos positivos provenientes da inovação em produto, conforme respostas elencadas na Tabela 7, os aspectos de maior destaque apontados pelas empresas, foram principalmente o aumento da qualidade final de seu produto e em novos processos produtivos, dos quais totalizaram cerca de $56 \%$ das respondentes. Por fim, o último questionamento nesta seção foi atribuído ao resultado sob a ótica da estratégia com a aplicação da inovação, como retrata a Tabela 8 . 
Tabela 8 - Resultados em estratégia obtidos com a aplicação da inovação.

\begin{tabular}{l|r|r}
\hline \multicolumn{1}{c}{ RESULTADO } & QTDADE & \% \\
\hline Atingir a liderança de mercado & 8 & 17,02 \\
\hline Aumento da competitividade & 10 & 21,28 \\
\hline Crescimento da marca & 2 & 4,26 \\
\hline Desenvolvimento de novos produtos & 1 & 2,13 \\
\hline Geração de ideias & 4 & 8,51 \\
\hline Maior alcance de clientes & 3 & 6,38 \\
\hline Melhora do relacionamento com fornecedores & 1 & 2,13 \\
\hline Melhora no planejamento & 5 & 10,64 \\
\hline Verticalização da cadeia produtiva & 2 & 4,26 \\
\hline Não sabe & 6 & 12,77 \\
\hline Nenhum & 5 & 10,64 \\
\hline TOTAL & $\mathbf{4 7}$ & $\mathbf{1 0 0 , 0 0}$ \\
\hline
\end{tabular}

Fonte: Elaborado pelos autores a partir dos dados coletados (2020).

Desse modo, a Tabela 8 deixa claro que para as empresas deste estudo, o aspecto de retorno em relação a estratégia obtidos a partir de práticas inovadoras é bem pulverizado entre as opções elencadas, no entanto, percebe-se uma concentração no resultado de aumento da competitividade e atingimento de liderança de mercado, das quais representaram $21,28 \%$ e $17,02 \%$ respectivamente, compreendendo resposta de 18 empresas, mais de $1 / 3$ da amostra da pesquisa.

\subsection{PARTICIPAÇÃO E GERAÇÃO DA INOVAÇÃO}

Em cumprimento a análise e discussão dos resultados, esta seção ainda aborda as respostas relativas a questionamentos do Módulo IV, no entanto, trata da Participação e Geração da Inovação no contexto de desenvolvimento de novos produtos, no design ou embalagem dos produtos, na alteração dos métodos de venda, além de tratativas acerca da inovação na logística, melhoria do suporte e na criação ou aquisição de marcas e da participação da inovação em novos processos industriais, novas formas de gestão e em desenvolvimentos de serviços diferenciados. Com isso, a Tabela 9 evidencia as respostas elencadas pelas empresas, a partir da participação da inovação no desenvolvimento de novos produtos, no design/embalagem e na alteração dos métodos de venda. 
Tabela 9 - Participação da inovação no desenvolvimento de novos produtos, no design ou embalagem e na alteração dos métodos de venda.

\begin{tabular}{l|c|c|c|c|r|r}
\hline \multicolumn{1}{c|}{ RESPOSTA } & $\begin{array}{c}\text { DESENV. } \\
\text { NOVOS } \\
\text { PRODUTOS }\end{array}$ & $\%$ & $\begin{array}{c}\text { DESIGN OU } \\
\text { EMBALAGEM }\end{array}$ & \% & $\begin{array}{l}\text { MÉTODOS } \\
\text { DE VENDA }\end{array}$ & $\%$ \\
\hline Discordo totalmente & 3 & 6,38 & 5 & 10,64 & 4 & 8,51 \\
\hline Discordo & 4 & 8,51 & 7 & 14,89 & 6 & 12,77 \\
\hline Neutro & 5 & 10,64 & 14 & 29,79 & 8 & 17,02 \\
\hline Concordo & 21 & 44,68 & 14 & 29,79 & 24 & 51,06 \\
\hline Concordo totalmente & 14 & 29,79 & 7 & 14,89 & 5 & 10,64 \\
\hline TOTAL & $\mathbf{4 7}$ & $\mathbf{1 0 0 , 0 0}$ & $\mathbf{4 7}$ & $\mathbf{1 0 0 , 0 0}$ & $\mathbf{4 7}$ & $\mathbf{1 0 0 , 0 0}$ \\
\hline
\end{tabular}

Fonte: Elaborado pelos autores a partir dos dados coletados (2020).

A partir da análise da frequência entre as opções de reposta das empresas em relação a concordância, não concordância ou neutralidade diante dos quesitos perguntados, percebe-se um agrupamento na resposta em que as organizações concordam no desenvolvimento de novos produção, em grande maioria com quase $45 \%$, no item de design/embalagem foram apontadas por 14 empresas, representando $29,79 \%$ das respondentes e sobre os métodos de venda, mais da metade das empresas destacaram concordância sobre o aspecto da presença da inovação.

De modo geral, a análise da Tabela 9 permite constatar mais números positivos no que tange a presença da inovação nas organizações, do que negativos, visto que, a maioria das respostas foram elencadas entre a opção "Neutro" e "Concordo totalmente", o que dessa forma pode ser atribuído de fato pela participação inovadora nos quesitos citados anteriormente e ao mesmo tempo visto os resultados trazidos pelo processo de práticas inovadoras.

Ainda no que se refere a participação da inovação, a Figura 4 ilustra como se dá esse processo diante da logística, do suporte e na criação ou aquisição de marcas para as empresas participantes deste estudo. 
Figura 4 - Participação da inovação na logística, melhoria do suporte para os sistemas de manutenção, contabilidade ou informática e na criação ou aquisição de marcas.

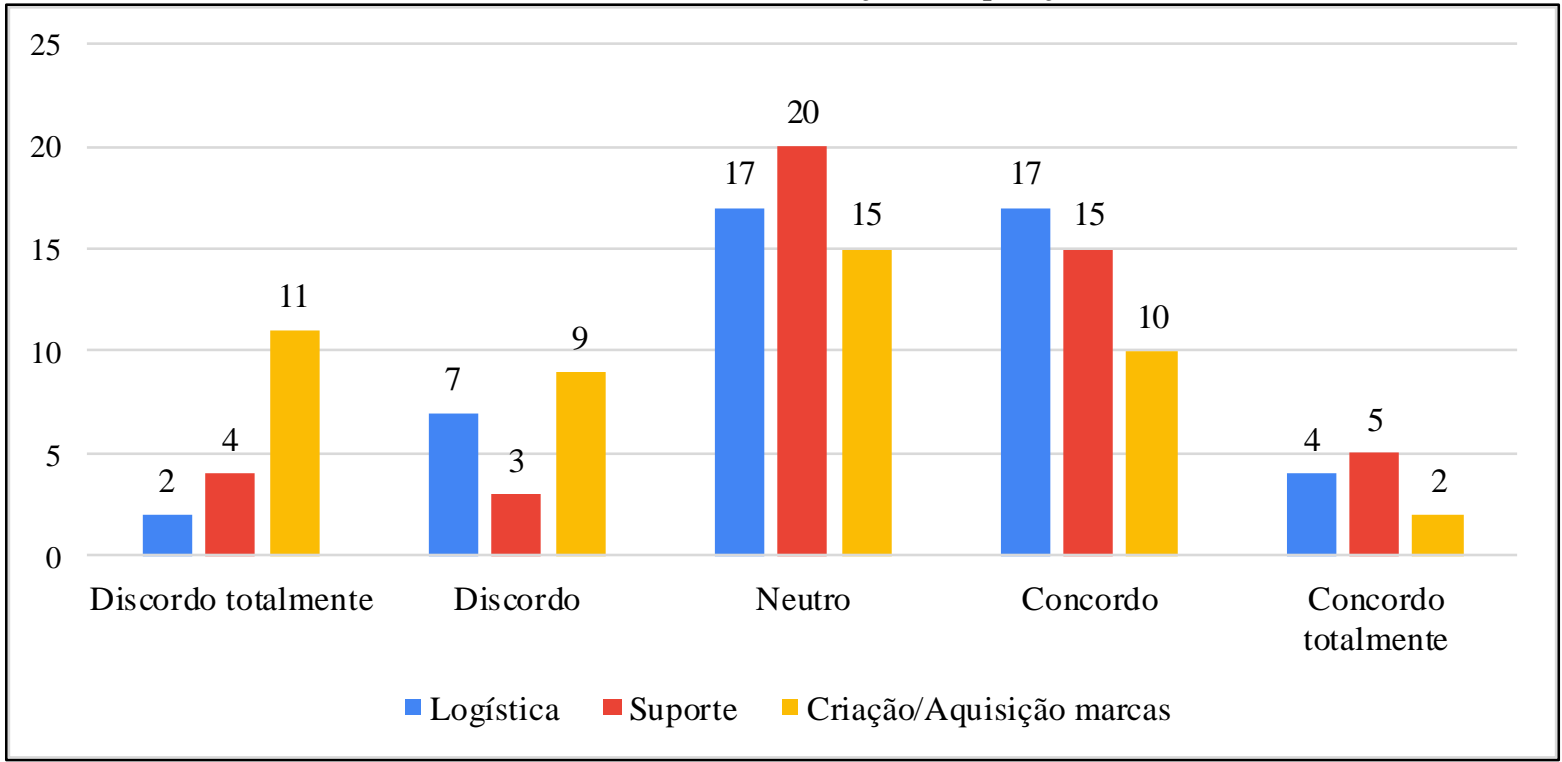

Fonte: Elaborado pelos autores a partir dos dados coletados (2020).

Tendo em vista que as práticas inovadoras não devem ser vistas apenas pela área tecnológica, as empresas tendem a utilizar a inovação nos diversos setores que a compõem. Entretanto, a Figura 4 revela uma realidade diferente nas empresas participantes deste estudo, já que em "concordância total" com a afirmativa da participação de práticas de inovação nas áreas de logística e distribuição; suporte para os sistemas de manutenção; e criação ou aquisição de marcas, apenas 4,5 e 2 empresas respectivamente apontaram tal resposta, o que representa uma média de $7,8 \%$ do total da amostra deste estudo.

De modo geral, as empresas, se posicionaram em sua maioria como neutras perante as áreas aqui citadas, como evidenciado na figura, em que há a maior concentração de respostas.

Enfim, no que tange as práticas de inovação em novos processos industriais, novas formas de gestão e desenvolvimentos de serviços, a Tabela 10 apresenta os apontamentos realizados pelas respondentes da pesquisa. 
Tabela 10 - Participação da inovação em novos processos industriais, na adoção de novas formas de gestão e em

\begin{tabular}{l|c|c|c|c|c|r}
\multicolumn{1}{c}{ RESPOSTA } & $\begin{array}{c}\text { NOVOS } \\
\text { PROCESSOS } \\
\text { IND. }\end{array}$ & $\%$ & $\begin{array}{c}\text { NOVAS } \\
\text { FORMAS } \\
\text { GESTÃO }\end{array}$ & $\%$ & $\begin{array}{c}\text { DESENV. } \\
\text { DE } \\
\text { SERVIÇOS }\end{array}$ & $\%$ \\
\hline Discordo totalmente & 0 & 0,00 & 4 & 8,51 & 4 & 8,51 \\
\hline Discordo & 6 & 12,77 & 3 & 6,38 & 2 & 4,26 \\
\hline Neutro & 13 & 27,66 & 20 & 42,55 & 19 & 40,43 \\
\hline Concordo & 21 & 44,68 & 15 & 31,91 & 17 & 36,17 \\
\hline Concordo totalmente & 7 & 14,89 & 5 & 10,64 & 5 & 10,64 \\
\hline TOTAL & $\mathbf{4 7}$ & $\mathbf{1 0 0 , 0 0}$ & $\mathbf{4 7}$ & $\mathbf{1 0 0 , 0 0}$ & $\mathbf{4 7}$ & $\mathbf{1 0 0 , 0 0}$ \\
\hline
\end{tabular}

Fonte: Elaborado pelos autores a partir dos dados coletados (2020).

Dessa forma, a análise compreende que para a presença de inovação em novos processos industriais 44,68\% das respondentes concordam com tal afirmação, já no que se refere a adoção de novas formas de gestão e desenvolvimento de serviços diferenciados, há maior concentração de respostas na situação de neutralidade, destacadas por $42,55 \%$ e $40,43 \%$ das empresas respectivamente.

\section{CONSIDERAÇÕES FINAIS}

O processo de estreitamento das relações comerciais vem sendo conquistado principalmente pelo advento da globalização e os avanços tecnológicos, também marcados pela formação de blocos regionais que possibilitaram uma integração entre os países. Com isso também se deu a quebra de barreiras comerciais, objetivando a facilitação comercial entre as nações, tendo em vista a necessidade da internacionalização das empresas para sua sobrevivência, acarretando a propagação de organizações multinacionais.

Nesse contexto de formação de parcerias a partir das relações de comércio além das fronteiras, se destaca a importância da inovação para as empresas no trâmite da internacionalização. No que tange o desempenho das exportações, a presença de práticas inovativas tanto de produtos, como processos, tem papel fundamental para a inserção internacional de êxito, além disso, a própria operação de exportação pode gerar inovação para a empresa, uma vez que o contato com o mercado internacional garante acesso a informações e outras redes de relacionamento que beneficiam a organização nesse aspecto.

Tendo em vista o processo de internacionalização das empresas exportadoras pertencentes a microrregião da AMREC, o estudo constatou que se trata de organizações 
fundadas a partir da década de 1950, em sua maioria situadas nas cidades de Criciúma, Içara e Morro da Fumaça, que mantêm negócios primordialmente com o mercado interno, porém comercializam seus excedentes no âmbito internacional, em que, compõem os mais variados setores de atuação, tendo como destaque, o setor Metal mecânico, o de Produtos Químicos e Plásticos e o setor Cerâmico.

No que se refere ao âmbito da inovação, no contexto dos resultados obtidos com a aplicação de práticas inovativas, tem-se como destaque apontado pelas empresas, o aumento de faturamento, no aspecto financeiro, aumento na percepção de valor da marca, a partir do resultado com o cliente, e em relação ao produto, houve uma concentração de respostas na atribuição de aumento na qualidade final da sua produção.

Logo, sobre a participação e geração da inovação para as empresas, o estudo revelou maior concordância em relação a essa afirmação, junto ao desenvolvimento de novos produtos, alteração dos métodos de venda e em novos processos industriais, sendo os que obtiveram maior concentração de respostas para a opção. No entanto, cerca de $40 \%$ das empresas deste estudo posicionaram-se neutras diante da presença e a produção de inovação à adoção de novas formas de gestão e no desenvolvimento de serviços diferenciados.

De modo geral, diante da pesquisa discutida tem-se uma visão que tais organizações se relacionam com o processo inovativo diante de operações mais "palpáveis", sendo essas atribuídas ao produto, enquanto desenvolvimento, na utilização de novos processos industriais e consequentemente na qualidade final do mesmo, tendo uma característica bem acentuada no que envolve o processo produtivo como um todo.

Com isso, diante da explanação, que se limitou ao perfil e contexto inovativo de empresas exportadoras do sul catarinense, sugere-se a aplicação do mesmo questionário aqui utilizado, à empresas exportadoras da microrregião da AMESC (Associação dos Municípios do Extremos Sul Catarinense) e AMUREL (Associação dos Municípios da Região de Laguna), tendo por base o aumento da população e atingimento a mais empresas situadas no extremo sul do estado, o que possibilitaria um levantamento mais amplo do perfil das organizações da região como um todo. 


\section{AGRADECIMENTOS}

À Fundação de Amparo à Pesquisa e Inovação do Estado de Santa Catarina (FAPESC) e a Associação Catarinense das Fundações Educacionais (ACAFE), por meio da chamada pública 06/2017, contrato 2018TR1542 e protocolo de entrada 1673/2018, contemplando uma pesquisa com amplitude maior, intitulada "Do Sul Catarinense (AMREC) para o mundo: exportação de práticas e soluções inovadoras".

Ao Grupo de Pesquisa Gestão e Estratégia em Negócios Internacionais - GENINT da Universidade do Extremo Sul Catarinense - UNESC.

\section{REFERÊNCIAS}

Almeida, A. (org.). (2007). Internacionalização de empresas brasileiras: perspectivas $e$ riscos. Rio de Janeiro: Elsevier, Disponível em: https://books.google.com.br/books?id=s25xBjryzTQC\&amp;printsec=frontcover\&amp;hl=pt-

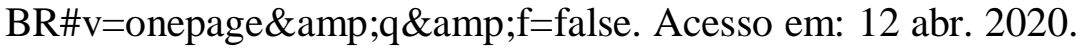

AMREC. Associação dos Municípios da Região Carbonifera. (2020). Municípios associados. Disponível em: https://www.amrec.com.br/index/municipiosregiao/codMapaItem/140366. Acesso em: 30 mar. 2020.

Barros, A. J. da S.; Lehfeld, N. A. de S. (2007). Fundamentos de Metodologia Científica. 3. ed. São Paulo: Pearson Universidades, 176 p.

Brasil. ANVISA. (2019). Porte da empresa. Disponível em: http://portal.anvisa.gov.br/porte-de-empresa. Acesso em: 13 abr. 2020.

Brasil. IBGE. (2017). Conheça cidades e estados do Brasil. Disponível em: https://cidades.ibge.gov.br/. Acesso em: 04 abr. 2020.

Brasil. Ministério da Economia. Estatísticas de comércio exterior. (2019). Empresas brasileiras exportadoras e importadoras. Disponível em: http://www.mdic.gov.br/index.php/comercio-exterior/estatisticas-de-comercioexterior/empresas-brasileiras-exportadoras-e-importadoras. Acesso em: 10 jan. 2020.

Bustus, P. (2011). Trade liberalization, exports and technology upgrading: evidence on the impact of MERCOSUR on argentianian firms. American Economic Review. Nashville, v. 101 n. $1, \quad$ p. 304-340, fev. Disponível em: https://www.aeaweb.org/articles?id=10.1257/aer.101.1.304. Acesso em: 13 abr. 2020. 
Caldera, A. (2010). Innovation and exporting: evidence from spanish manufacturing firms. Review of World Economics. [s.1.], v. 146, v. 4, p. 657-689, dez. Disponível em: https://ideas.repec.org/a/spr/weltar/v146y2010i4p657-689.html. Acesso em: 14 abr. 2020.

Cassiman, B.; Golovko, E. (2011). Innovation and internationalization through exports. Journal of International Business Studies. Nova York, v. 47, n. 1, p. 56-75. Disponível em: https://econpapers.repec.org/article/paljintbs/v_3a42_3ay_3a2011_3ai_3a1_3ap_3a5675.htm. Acesso em: 13 abr. 2020.

Chesbrough, H. W. (2003). Managing open innovation. Research Technology Management. Baadba, v. 47, n. 1, p. 23-64, dez. Disponível em: https://www.researchgate.net/publication/233719519_Managing_Open_Innovation. Acesso em: 14 abr. 2020.

Cooper, R.G. (1992). The NewProd system: the industry experience. Journal of Product Innovation Management. Nova York, v. 2, n. 9, p. 113-127, maio. Disponível em: https://www.researchgate.net/publication/222603644_The_NewProd_System_The_Industry_ Experience. Acesso em: 13 abr. 2020.

Costa, L. de F. L. G. da; Añez, M. E. M.; Mol, A. L. R.; Damasceno, T. dos S. A. (2017). Escolas teóricas do processo de internacionalização: uma visão epistemológica. Cadernos Ebape. Rio de Janeiro, v. 15, n. 4, p. 960-973, dez.

Creswell, J. W. (2010). Projeto de pesquisa: Métodos qualitativo, quantitativo e misto. 3. ed. Porto Alegre: Artmed.

Diehl, A. A.; Tatim, D. C. (2004). Pesquisa em ciências sociais aplicadas: métodos e técnicas. São Paulo: Pearson Prentice Hall.

Dondossola, A.; Zilli, J. C.; Volpato, D.; Vieira, A. C. P. (2019). Internacionalização de empresas brasileiras: o caso de uma exportadora de arroz. Revista Gestão \& Sustentabilidade $R G \& S$, v. 1, p. 1-20.

Duarte, S. V.; Furtado, M. S. V. (2014). Trabalho de conclusão de curso (TCC) em ciências sociais aplicadas. São Paulo: Saraiva.

Engeroff, R.; Balestrin, A. ( 2008). Inovação fechada versus inovação aberta: um estudo de caso da indústria de cutelaria. In: SIMPÓSIO DE GESTÃO DA INOVAÇÃO TECNOLÓGICA, 25, 2008. Anais eletrônicos [...]. Brasília: ANPAD.

Estrela, C. (org.). (2018). Metodologia científica: ciência, ensino e pesquisa. 3. ed. Porto Alegre: Artes Médicas, 711 p. Disponível em: http://www.bib.unesc.net/pergamum/biblioteca/index.php. Acesso em: 14 abr. 2020.

Gil, A. C. (1999). Métodos e técnicas de pesquisa social. 5. ed. São Paulo: Atlas.

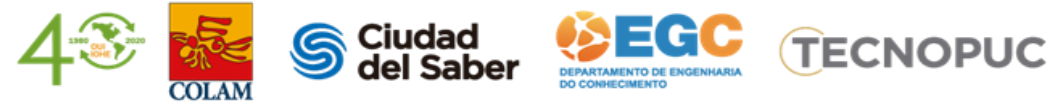


Goulart, L., Arruda, C. A., Brasil, H. V. (1994). A evolução na dinâmica de internacionalização. Revista Brasileira de Comércio Exterior, v. 1, n. 41, p. 31-40, out./dez. Disponível em: http://acervo.ci.fdc.org.br/AcervoDigital/Artigos\%20FDC/Artigos\%20FDC\%201994/Revista \%20RBCE.pdf. Acesso em: 30 mar. 2020.

Grossman, G. Helpman, E. (1991). Innovation and growth in the global economy. Cambridge: MIT Press.

Lakatos, E. M.; Marconi, M. de A. (2001). Fundamentos de metodologia científica. 4. ed. rev. e ampl. São Paulo: Atlas.

Levitt, T. (19830. The globalization of markets. Harvard Business Review, v. 2, n. 3, p. $13-23$, jul./dez. Disponível em: https://www.researchgate.net/publication/228123514_Theodore_Levitt's_'The_Globalization_ of_Markets'_An_Evaluation_after_Two_Decades. Acesso em: 30 mar. 2020.

Loureiro, F. A., Santos, S. A. (1991). Internacionalização de Empresas Brasileiras. Revista de Administração. Rio de Janeiro, v. 28, n. 1, p. 23-24, jan./mar. Disponível em: https://www.academia.edu/7416631/LOUREIRO_SANTOS_1991_Internacionalizacao_de_e mpresas_brasileiras. Acesso em: 14 abr. 2020.

Malhotra, N. K. (2005). Introdução à pesquisa de marketing. São Paulo: Prentice Hall.

Malhotra, N. (2006). Pesquisa de marketing: uma orientação aplicada. 4.ed. Porto Alegre: Bookman.

Marconi, M. de A.; Lakatos, E. M. (2017). Fundamentos de metodologia científica. 8. ed. São Paulo: Atlas, 338 p. Disponível em: http://www.bib.unesc.net/pergamum/biblioteca/index.php. Acesso em: 14 abr. 2020.

Melitz, M. J. (2003). The impact of trade on intra-industry reallocations and aggregate industry productivity. Econometrica. New Haven, v. 71, n. 6, p. 1695-1725, nov. Disponível em: https://www.jstor.org/stable/1555536?seq=1. Acesso em: 13 abr. 2020.

Meloan, T. W., Graham, J. L. (1998). International and global marketing: concepts and cases. Boston: Irwin/McGraw-Hill.

Miranda, K. F.; Vasconcelos, A. C. de; Luca, M. M. M. de; Cabral, J. E. de O. (2015). A capacidade inovativa e o desempenho econômico-financeiro de empresas inovadoras brasileiras. Revista Eletrônica de Administração (READ), [s.1.], v. 21, n. 2, p. 269-299, ago. Disponível em: http://www.scielo.br/scielo.php?pid=S141323112015000200269\&script=sci_abstract\&tlng=pt. Acesso em: 13 abr. 2020. 
Nascimento, L. P. do. (2012). Elaboração de projetos de pesquisa monografia, dissertação, tese e estudo de caso, com base em metodologia científica. São Paulo: Cengage Learning Ltda, 149 p. Disponível em: http://www.bib.unesc.net/pergamum/biblioteca/index.php. Acesso em: 14 abr. 2020.

Pereira, J. R.; Zilli, J. C.; Vieira, A. C. P.; Volpato, D. (2018). Business internationalization: decisive factors for decision-making. Brazilian Journal of Development, v. 4 , p. $472-501$.

Reichert, F. M.; Camboim, G. F.; Zawislak, P. A. (2015). Capacidades e trajetórias de inovação de empresas brasileiras. Revista de Administração Mackenzie, São Paulo, v. 16, n. 5, p. 161-194, out. Disponível em: http://www.scielo.br/scielo.php?script=sci_arttext\&pid=S1678-

69712015000500161\&lng=pt\&tlng=pt. Acesso em: 14 abr. 2020.

Sampieri, R. H.; Collado, C. F.; Lucio, M. P. B. (2013). Metodologia de pesquisa. 5. ed. Porto Alegre: Penso.

SEBRAE. (2020). Painel de empresas. Disponível em: https://datasebrae.com.br/totaldeempresas/. Acesso em: 04 abr. 2020.

Teece, D. J.; Pisano, G. (1993). The dynamic capabilities of firms: an introduction. Industrial and Corporate Change. Oxford, v. 3, n. 3, p. 537-56, dez. Disponível em: https://www.researchgate.net/publication/235362985_The_Dynamic_Capabilities_of_Firms_ An_Introduction. Acesso em: 14 abr. 2020.

Tidd, J.; Bessant, J.; Pavitt, K. (2003). Gestão da Inovação. Integração de mudanças Tecnológicas, de mercado e organizacionais. Lisboa: Monitor.

Van Der Meer, H. (2007). Open innovation - The dutch treat: challenges in thinking in business Models. Creativity and Innovation Management. [s.l.], v. 16, n. 2, p. 192-202, maio. Disponível em: https://www.researchgate.net/publication/227673378_Open_Innovation__The_Dutch_Treat_Challenges_in_Thinking_in_Business_Models. Acesso em: 04 abr. 2020.

Vergara, S. C. (2010). Métodos de pesquisa em administração. 4. ed. São Paulo: Atlas.

Zilli, J. C.; Heinzen, M.; Vieira, A. C. P. (2015). Estratégias e grau de internacionalização de empresas transformadoras de polímeros. Revista de Administração de Roraima-RARR. Boa Vista, v. 5, n. 1, p. 23-41, jul.

Zilli, J. C.; Locks, A. S.; ; Freire, P. S.; Engel, E. P. J. (2019). Innovation in the brazilian exporting companies. International Journal of Develpment Research, v. 6, p. 30909-30914.

Zilli, J. C.; Freire, P. S. (2020). The innovation in the ceramic tile exporting industries in Santa Catarina, Brasil International Journal of Develpment Research, v. 10, p. 34832-34837.

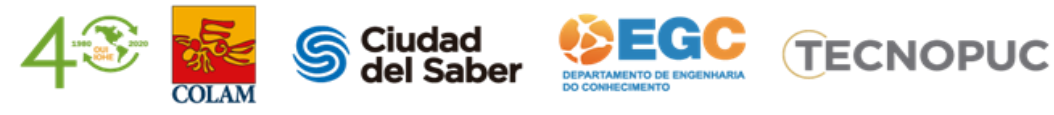

